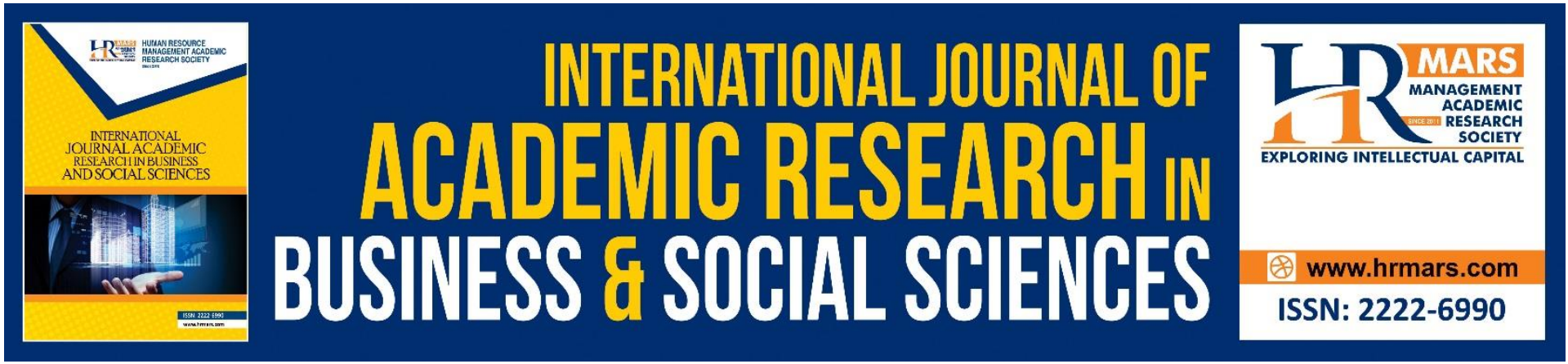

\title{
Comparative Analysis of Storytelling Technique in Kingdom Hearts II (2005) and Persona 3 Portable (2009)
}

\author{
Shazwin Bt. Sahmir, Norlela Ismail
}

To Link this Article: http://dx.doi.org/10.6007/IJARBSS/v10-i12/8357

DOI:10.6007/IJARBSS/v10-i12/8357

Received: 18 October 2020, Revised: 12 November 2020, Accepted: 28 November 2020

Published Online: 26 December 2020

In-Text Citation: (Sahmir \& Ismail, 2020)

To Cite this Article: Sahmir, S. B., \& Ismail, N. (2020). Comparative Analysis of Storytelling Technique in Kingdom Hearts II (2005) and Persona 3 Portable (2009). International Journal of Academic Research in Business and Social Sciences. 10(12), 583-596.

Copyright: () 2020 The Author(s)

Published by Human Resource Management Academic Research Society (www.hrmars.com)

This article is published under the Creative Commons Attribution (CC BY 4.0) license. Anyone may reproduce, distribute, translate and create derivative works of this article (for both commercial and non-commercial purposes), subject to full attribution to the original publication and authors. The full terms of this license may be seen at: http://creativecommons.org/licences/by/4.0/legalcode

\section{Vol. 10, No. 12, 2020, Pg. 583 - 596}

Full Terms \& Conditions of access and use can be found at http://hrmars.com/index.php/pages/detail/publication-ethics 


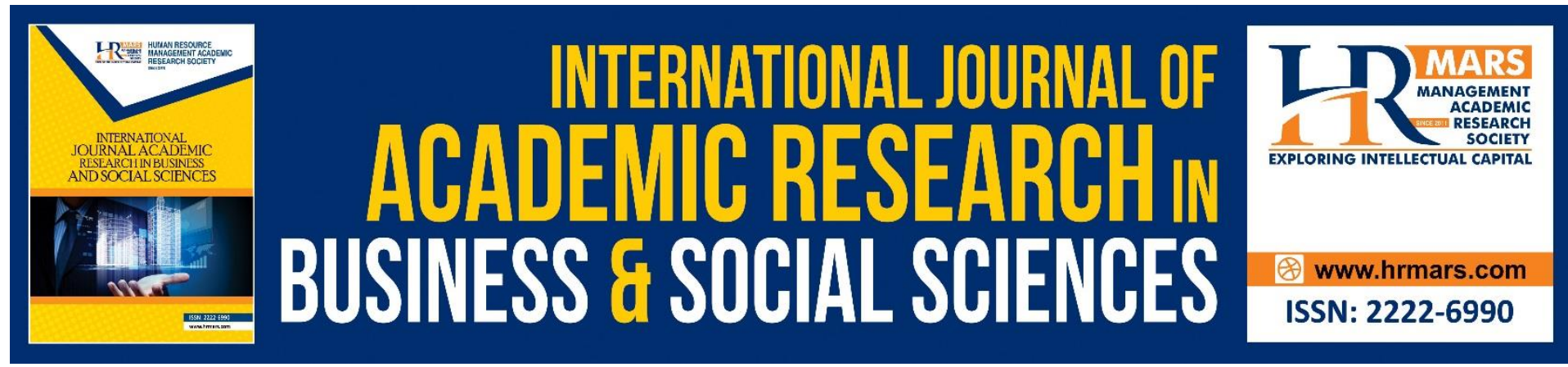

\title{
Comparative Analysis of Storytelling Technique in Kingdom Hearts II (2005) and Persona 3 Portable (2009)
}

\author{
Shazwin Bt. Sahmir, Norlela Ismail \\ Faculty of Film, Theatre and Animation, Universiti Teknologi Mara, Malaysia \\ Email: celidenima@gmail.com,norlelai@uitm.edu.my
}

\begin{abstract}
Playing video games is a popular trend for generations in the modern era. In the video game, players can enjoy distinct stories and characters. Stories that are presented in various storytelling techniques. This essay attempts to identify the storytelling technique through the mechanics of video games. However, a story in a video game is argued to be diminishing the experience of gameplay (Stein, 2016). Some directors tend to make a convoluted plot and back story that does not have proper context, which ends up being a frustration to players (Danggi, 2017). This makes them much less impactful as well-spent entertainment. Nonetheless, this essay argues that games can be fun to engage in, their stories have interesting plotline and backstory, also has lore that can be explored further. The Spatial Presence Theory is employed through a comparative analysis of two video game texts entitled Kingdom Hearts II (2005) and Persona 3 Portable (2009).
\end{abstract}

Keywords: Video Games, Storytelling Technique, Kingdom Hearts II, Persona 3 Portable, Comparative Analysis

\section{Introduction}

The first video game of single and multiplayer ever existed is 'Pong' in 1972 ("Atari Pong", n.d.). The first game that rises in the market of a 2-dimensional graphic that estimated to plummet in the year 1993. But, this proven wrong as numerous games have been evolved and released without showing any signs it will end. From a text-based adventure to a 3dimensional graphic with a $360^{\circ}$ camera movement, games have evolved from an entertainment device to a piece of art (Hurme, 2016). Since it has been regarded as a piece of art, the notions of gameplay and storytelling are crucial. The gameplay is the actions taken by the player with the narrative taken account of these actions (Ang, 2005). With players abide by the game rules that exist within a narrative space, it makes the story consistent and coherent. Games such as The Legend of Zelda series and Final Fantasy series follow this trend as a high-selling Role-Playing Game (RPG). Games of the RPG genre are more inclined to be dependent on a good storyline as the player is playing a role given to them (Christy, 2010). Unlike adventure where freedom is vast, there is an ending to achieve. Heavy story 
and displeasing gameplay can result in becoming a bad game, but not for Kingdom Heart II and Persona 3 Portable.

Storytelling is the art of telling a story that makes the audience immersed ("The power of storytelling", n.d.). Whether it is in the form of books, films, or games, the message and information must be relayed without vague. Different techniques can be used to convey them ("List of narrative techniques", 2017). It is up to the game designer which device is suitable for the layout of their story. Their plots can consist of backstory, flashback, foreshadowing, or frame story where there is a story within a story. They can choose their perspective to use the typical first, second, or third view. Other than these, they can choose the wider vision in multi-perspectivity, a stream of consciousness in monologue, magical realism, and much more.

There is a range of storytelling techniques that can be used, nonetheless, Stein argues that if the techniques are not carefully employed, they can lessen the value of gameplay (2016). What makes a game so memorable is the struggle to find treasures, grinding levels, and Easter egg discovery around the game world. However, when the story becomes the main focus, gameplay becomes less enjoyable. According to Dangcil (2017), Kingdom Hearts has stories of convoluted plots and plot holes that make them confusing. It makes the head stirred even more realizing the game's timeline does not parallel to their date of release, more frustrating with the release on different platforms. It is being accused of making up stories as the series goes. Stuart also thinks that some game developer likes to do narrative carpetbombing hoping that it could leave an impact, thinking that thousands of backstories with thousands of characters is considered deep narratives (2016). The extra components they gave that existed without proper context is meaningless to the player.

This raises some questions on game capability in storytelling. How can the storytelling technique be executed? What are the elements that strongly help in engaging the story within a game? Do the games listed, Kingdom Hearts II and Persona 3 Portable, able to deliver their story efficiently? This paper argues that these video games, Kingdom Hearts II and Persona 3 Portable, are fun and enjoyable to play despite its convoluted plot. Their stories are easy to understand and have little plot holes, though Kingdom Hearts II may have less lore than the other. Thus, this paper aims:

a) To analyze the texts of both games through the framework of Spatial Presence Theory where the key component of Immersion Factors will be discussed

b) To compare the texts of both games in terms of its storytelling techniques.

Pickvane states that comparative analysis defines as the aim to explain the differences or similarities of texts and to identify underlying causal patterns present between two texts (2001).

\section{Video Narrative}

Generally, narrative in video games exists in many forms, it depicts all the basic structure of a story such as characters, events, plots, settings, and themes which ultimately lead the beginning of a narrative to the end (Lemmens, 2016). Games have a unique achievement for creating an integrated play within the narrative and fictional framework. The integrated play must be delivered through the agents of action, which is character. The presence of characters is important to drive the story forward. Players that immerse themselves in the gameplay hold an important role, as it gives results through their mechanical input. Whether the story is predetermined or not, the narrative will be able to process when the player voluntarily helps in constructing the story. 
On the other hand, micro-narratives are one of the pertinent concepts that are found in video games. The micro-narrative is to tell side stories that relate to the main story however if the perspective of the story changes from one character to another in the narrative, narrative arcs will emerge. According to Bizocchi in Pieter Lemmens (2016), the narrative arc is as a "smaller moments of narrative flow and coherence that occur within a broader context of gameplay" (p. 19). Through the narrative parameters of the story world, characters, and emotion, players can obtain crucial information by interacting with Non-Playable Characters (NPC) or the players could also collect key points throughout the journey anticipating what is to come.

A scripted trajectory is another key concept in video games. It is a form of interactive narrative that applies in RPG (Lemmens, 2016). Players are instructed to explore areas of the game world and given the choices to pick which one they want to visit first. This is a perfect set up for a linear storyline as there can only be one right end position that makes the game progress. Cut scenes are played when the players gained achievement of new areas, unlocked events, or completing objectives and quests. Although, this scripted narrative style has the player's hand-tied since information is being shoved to them directly. This is considered as a 'push' narrative, the player is given more than they can absorb whereas, 'Pull' narrative influences or engages the players to uncover more reasons to explore the story (Crafty TV Writing, n.d). Players play their part in progressing the story whichever way fits, through their comprehension and also depends on their ability to immerse in the narrative texts.

\section{Storytelling Techniques in Video Games}

In the research of Slota Stephen, Young Michael, Travis Roger, and Choi Beomkyu (2015) entitled, Game Narrative, Interactive Fiction, and Storytelling: Creating a "Time for Telling" in the Classroom", there are three groups under player-game-narrative interaction games. For starters, there are games with narratives pre-grounded in transmedia storytelling across movies, books, and others like Star Wars for example. Then, some games have an elaborate history built within the narrative but not necessarily an extension of existing transmedia storytelling. An example is BioShock by $2 K$ Games. Lastly are games with a straightforward narrative that simply serves to play which are Angry Birds and Plants vs. Zombies as an example. Despite its approach to simplicity, this could omit a range of possibilities in narrative affordances not encompassed within the game developer framework. An unexpected emergent player goal may lead to unique player-constructed narratives. The games' ruleset offers affordances to gameplay that can deviate wildly from the games' original goal, like Grand Theft Auto IV. This allows the player to adapt, learn, and modify the games they play.

Within a video game narrative, there are three levels so far and the first level tells the game narrative as designed (Slota et al, 2015). The problem within this level is that it is easily altered by the player who finds greater value in reshaping the story based on their own goals and intentions. This brings us to level two that is the player's individualized experience of game narrative that leads to the player-generated narrative. In level three, however, it consists of social collaboration that immediate the realm of play. These affinity groups emerge as a result of gameplay into fan clubs that alter both the narrative-as-designed and player-generated narrative. Their purpose is to share cheats, hints, and guides to co-creation or management of fan fiction and game mods. It encourages them to discussion on topics like ideal group composition or the canonical importance of a particular mission. 
The differentiation of narrative levels within video games is concerned between gaming and storytelling that tends to devolve into a convoluted storyline with blurred terminology and problems of subjectivity (Slota et al, 2015). The research relies on a more sophisticated approach to gaming and narrative that draws contemporary learning theory of situated cognition and the rich contexts in gameplay and storytelling merge with real-world application, that is performative play practice as in performative-interpretive method.

\section{Spatial Presence Theory - Immersion factors}

In the article entitled, The Psychology of Video Games (Madigan, 2010), spatial presence theory is a relation to immersion factors in video games. Two levels within the theory are the spatial situation model and spatial presence. The spatial situation model has controlled and automatic attention that attracts the player's attention whereas spatial presence relates to the perceptual hypothesis that influences high levels of involvement and suspension of disbelief. In simpler words, representation is formed in the player's mind of the game world and referred to them for where they are. This happened when cues like images and sounds cooperate along with anticipations on what the journey will bring. Once the mental model of the game world is formed, It is up to players to consciously or unconsciously involved in the imagined world or not.

There exist two characteristics of immersion to provide spatial presence (Madigan, 2010). The first one is immersion that creates a mental model of the game environment by providing complete multiple sensory information, cognitively demanding environments, and a strong interesting narrative. A complete multiple sensory information will work in tandem not to leave gaps for players to fill in with their imaginations. There will be fewer blanks mental models to avoid abstractions and contrivances that would interfere with the player's immersion. Cognitively demanding environments have the player focus on what is happening and getting by in the game, allowing them to be immersive while navigating the world. Finally, an interesting narrative can immerse the player by making the world seems believable.

The second one is immersion that creates consistency between things in-game environments (Madigan, 2010). A game with consistency immersion lacks visual cues, consistent believable behaviours from things, unbroken presentation, and interactivity with items. Incongruous visual cues remind the player that they are merely playing video games with advertisements pop up or tutorial messages that could ruin immersive gameplay. Next, believable behaviour from things means that everything from characters to objects behaves like the player expects them to. It should make sense and constant throughout the game. An unbroken presentation meaning that the spatial cues of the game world should not vanish. But this may break down regardless of the presence of a loading screen or game menu that disrupts the immersion. Lastly is interactivity with items where it gives feedbacks on actions between various parts of the environment. Non-playable characters (NPC) speech or operating machines that fit in the game world should give a sense of consistency and deem as convenient for players.

\section{Text Analysis I - Kingdom Hearts II}

A game contains enough entertainment value and variability in a story that makes the player plays it numerous times to see the offered alternative game experience if present (Christy, 2010). A game as such makes their replayability higher than most games compared to a strongly linear one. The beginning of the story Kingdom Hearts // starts from Roxas' point of view, his experience and time during his summer vacation in Twilight Town ("Kingdom Hearts 
II", n.d.). Bizarre events start to revolve around him, such as Nobody attacking him and strangers disturbing his daily life, as he starts dreaming about a strange boy wielding a giant key known as keyblade, a mysterious weapon wielded by Sora. Nobody is the shell of the body left behind after they turned into a Heartless, a being with hearts that lives on with the power of darkness. It is reminded that Sora has been turned into a heartless before. At the end of his story arc, it is revealed that he is Sora's Nobody and needs to return to him to wake him up. The story begins to expand more after Sora leaves Twilight Town to continue his journey home. During the middle, Sora, Donald, and Goofy travel around and help their friends in need of various worlds. At the same time, they are finding their way to reach King Mickey to find Riku while making sure Organization XIII, an evil Nobody organization, does not bring chaos to the world. The ending goes with Sora and Riku win their fight against Xemnas, the leader of Organization XIII. They come to a door of light in The World of Nothingness and brought to the shore in the Realm of Darkness. While they are stuck in a rut, another door to light opens before them. They return home in one piece once they stepped into the door, greeted by their friends on the shore of Destiny Island.

For Kingdom Hearts II, their events are pre-determined. There are the main ones and the side stories, Sora's story, and Disney's. The storytelling technique of this game is a scripted trajectory and micro-narratives. It is evident through Sora's visit to Disney's worlds in helping his friends in crisis with cut scenes revealing the worlds' current storyline. 'Push' narratives happen a lot of times since it contains thousands of cut scenes directing the player for the next course of action. It has a linear structure with scene branching since the player is allowed to go to whichever world they desire first and gives more freedom in engaging the story, though they will be routed back to the main storyline in the end.

The complication in this game has the typical light against darkness, person vs. person, Sora vs. Organization XIII. However, there is an inner conflict on Sora when he hesitates to eliminate Heartless as it only helps the Organization in completing Kingdom Hearts. Roxas also goes through this conflict when he refuses to disappear within Sora and wanted to exist as himself, but if he does not then Sora will never be awakened. The techniques used vary such as backstory where Roxas sees Sora's memories of the first game, an indication he is part of Sora. Flashback also happens where Roxas recalls his moments in betraying the Organization XIII and left to find Sora. A coincidental meeting with hooded Riku in Roxas' story arc is a foreshadowing they have met as it later reveals during Roxas' memories sequence. Frame story techniques can be seen in the variety of Disney's world story that exists in the main story of Kingdom Hearts II. The point-of-view revolves mostly around Sora but it also has multiple perspectives during certain cutscenes. For example, during the Pride Lands event where at first the cut scene focuses on Simba's conversation with Nala and moments later it pans back to Sora with Timon and Pumbaa chanting 'Hakuna Matata' as they enter the space. A character with good characterization can be indicated through their quality as a person and actions as well as speeches (Christy, 2010). Characterization brings the actor of the story to life with redeeming qualities that awed the audiences. Having relatable traits with the players is a bonus to have them immerse themselves into said characters. There are layers of depth within a character than what is shown to us.

Sora is the protagonist of the story and what drives the story forward ("Sora", n.d.). His name is derived from the Japanese Kanji (空) defined as the sky. Symbolism can be seen in his name as his heart is connected to every friend he met beside his ability to visit numerous worlds that share the same sky. He is illiterate in technology as he is an islander, it is proven during his times in Radiant Garden and Space Paranoids where he is confused by numbers of 
computer terms. His speech is mostly casual and laidback to give off the friendly aura he has that relieves everyone, allowing him to befriend them. Sora is an upbeat and simple-minded teenager that always willing to help a friend in need. He is aware of his duty to the world and does not hesitate to save it again. He is quick to anger when it comes to defending his friends, but he is sincere in what he says and has an unrelenting heart full of justice. When playing as a teenager, full of naivety and optimism, they can relate to Sora in a way of wanting to save the world from doom and going on an adventure to see the beautiful and interesting worlds.

Sora's character development is almost absent as he acts the same way as he is in the first game. The one who changes throughout the story probably goes to Roxas, his Nobody. The sub-theme inside the game is accepting oneself whether they are lacking personality, looks, or wealth. This could happen off-screen and tells a lot about how Roxas feels about being Sora's Nobody. Visiting the worlds gives hint to how Roxas probably feels and how important he is to Sora. In the end, after confronting Sora in his Heart Station, he gives in to the truth and become one with his true self. His drive sources are the friends around him. He wants to help them as much as he can and be relied on. Sora reminds us of the friendship the player has, reminding them of their naïve-self having fun with friends.

The level designer would be held responsible when building an environment in the game world as critically, interactively, and creatively as possible (Christy, 2010). They are to use art and programming tools to create a geographic region for the player to explore. The structure of level design must align with the navigation map at the corner of the screen. A certain level includes NPC that engage socially whereas Mobile Objects (MOB) a threatening enemies to defeat. Interactivity and immersion experience the game provided is maximized whether they come close to realism or not.

The Kingdom Hearts franchise mostly has their worlds consist of Disney's fantasy worlds such as Atlantica from The Little Mermaid franchise along with the films' respective characters appearing in the said world ("Kingdom Hearts II", n.d.). There are also a few original worlds created for this franchise such as Radiant Garden where notable Final Fantasy characters reside like Leon from Final Fantasy VIII. The environment is mostly fiction since Disney's worlds are almost identical to their film counterpart. An example would be Mulan's world The Land of Dragons from the palace, the snowy mountain, and the campsite, all mirroring the film's design and architecture. The stories revolve around said worlds do not alter much from the original as some scenes are identical to the movies. It gives a sense of nostalgia as well as connecting with their favourite Disney characters playing as Sora.

Even so, worlds in Kingdom Hearts II consist of interconnected flat rooms instead of sandbox open worlds. The excitement to explore secret areas is cut off, there is not a secret MOB either. There is no hidden treasure that rewards us for our witty discoveries or obtaining a new special skill from the secret boss fight. Although the player's movement is restricted, the rooms are expanded like tree branches. Each area is bound to connect to some rooms that can be accessed according to the map. The NPCs on the map area are less in number through interactive. Their purpose is to let players know their next step, reaction to certain events, or to shop for items and armors (Hurme, 2016). Sora can team up with Disney's characters too in fighting MOBs that are Heartless and Nobody. There are many types of these creatures that use different methods to defeat. Other than Heartless and Nobody, the cursed pirates in Port Royal and Organization XIII members are one of the unique MOBs the game offers. Interaction with objects in the world layout is possible but not much contains lore. One particular object that offers it is within the Twilight Town mansion where if interacted with 
the pods, it is said that some of it have been used before Sora. This could lead to a connection with the other games in the series hence the players are drawn to immerse in the game's world even further.

Choices exist in a game to determine the role of the player, the greater the freedom the more variety the experience (Christy, 2010). The player in Kingdom Hearts II is a minor character that sees behind the screen what happens to Sora as it tells in third-person view. They have no involvement in changing the storyline. Multi-perspectivity occurs as well where players can see through other perspectives such as Kairi or Diz throughout the game. This game's writing style is linear where the choices have been made and cannot be changed. The choices mostly are fake as the player needs to say 'Yes' to everything to proceed. The only 'No' they can choose is whether they want to repeat mini-games or refusing purchases. Though, other choices are available more in battle which is Summons, Reaction Commands, Limit Commands, and Drive Forms to let player strategize their combat system. They can change their party member at will but still cannot control them. The player can only play as Sora and his characteristics are already predetermined cutting off a bit of the player's immersive experience.

The auditory experience is also very crucial in playing the game, the background music or in short BGM will always come to mind. The music exists to enhance the emotion of the player during their gameplay, especially during a boss battle. The intense and fast-paced rhythm of the soundtrack makes the adrenaline gushes up, making it a fun and enjoyable fight. The field theme is also important to ensure it sets the right mood in the appropriate place at an appropriate time. The field theme can be considered as ambiance, it is a piece of music or sound that provides a basic environment understanding to the listener ("So... what are sound effects?", 2019). Soundtracks from the game are created by Yoko Shimomura, a freelance composer that used to work for Square Enix (Greening, 2007). When creating a composition, she takes up from Ludwig van Beethoven, Frederic Chopin, and Maurice Ravel that have influenced her music style. However, despite these influences and the classical training she goes through, her style is diverse throughout her career that may include pop, rock, chiptune, and more. One of her favorite tracks that she has created is Dearly Beloved from the first game of the series, Kingdom Hearts $I$.

Kingdom Hearts II may have the highest possibility of excellent immersion through sound as it has won Best Soundtrack in 2006. The BGM in the game acts as a medium of ambiance. Players can get a wild and adventurous vibe from Pride Lands BGM Adventures in the Savannah. On the other hand, Port Royal a world from Pirates of the Caribbean: The Curse of the Black Pearl uses a soundtrack from the movie itself. The battle theme He's a Pirate has the movie's chiptune arrangement from the renowned theme playing with the same name. It gives off the fun vibe from the film, the excitement, and nostalgia the player can get from their gameplay.

\section{Text Analysis II - Persona 3 Portable}

The plot starts when the protagonist comes to Tatsumi Port Island as a transfer student in his 2nd year ("Persona 3 Portable", n.d.). As he walks through the street towards his dorm, the Dark Hour comes and the environment changes to grim. The protagonist starts exploring through Tartarus to discover its secrets alongside the member of SEES. They gain new team members along their journey. The group of high school students shares lots of personal stories and lots of similarities between their struggles that they can bond. The group helps each other to cope, understand, and accept death as well as finding their reason to live, making their 
motivation to go through life. They work together to bring down Tartarus and get rid of the Shadows once and for all. A lot of people start to fall into Apathy Syndrome, suffering from debilitating levels of apathy. It starts to worsen when Strega shows up to put a stop to their journey by forming a cult and makes SEES go against each other. Ryoji then revealed to be the "Appraiser" of Nyx, a harbinger of Death, that will bring an end to the world. The team name then changes to Nyx Annihilation Team, indicating their change of goal to stop Nyx from plunging the world into destruction. It was vague in the PSP for the protagonist's ending but according to their partner in PS2, the protagonist gives up his soul to protect the door from opening. The protagonist spends their days until graduation with their comrades and finally leaves the surface world. The player does not know what their fate is but the metaphor of him closing his eyes tells a lot.

Persona 3 Portable storytelling technique is the same as Kingdom Hearts II, micronarratives, and scripted trajectory. The introduction to a new chapter of the story, like the protagonist's first arrival at Iwatodai dorm or engaging a new character's arc is considered their micro-narratives (Atlus, 2009). The 'Pull' narrative happens occasionally where they choose the best option in a conversation or more entertaining to see their reaction. Despite that, the 'Push' narrative also occurs since the player is a silent protagonist that only observes from the sidelines. They learn the story through NPC's conversation rather than voluntarily joining in. The high involvement of 'Pull' narratives is when players decide to explore NPCs' character arcs in expanding their Social Links, where it is their choice. There are some Social Links that they cannot escape like the Specialized Extracurricular Execution Squad (SEES). It does not affect the ending but gives a boost in their gameplay in strengthening their Persona.

The game's story is pretty linear since the main plot does not get affected by side events. The narrative structure present is hierarchical branching on characters' arcs whether to romance or not while the main story is scene branching where they can engage in different character's chapters but still push back to the main plot. The story's lore and knowledge are revealed bit by bit and explained clearly without sounding confusing. Even when the ultimate climax is reached, the plot moves along at the normal pace to give a sense of time moving slowly yet fast just like life.

There are numerous plot devices in this particular game. One of them is a backstory, if the players with the persimmon tree behind the school gym, the player can access to the old couple's Social Links at the bookstore by giving them the leaf. This is coincidentally a form of a frame story. Upon advancing their Social Links, the player will find out that a tree is a form of memento for their deceased son. They would have never guessed it can bring significance to the story but as they move deeper, it does to the NPC. During their interaction with the old couple will shove things into the inventory showing their care, a subtlety device. A flashback is also used during Mitsuru's first visit to Tartarus with her father to experiment on pieces of Plume of Dusk. Plot twist device can be seen on Shuji Ikutsuki where he is an ally of SEES the first half but betrayed them later for the revival of Nyx. The game used a multiperspective that juggles perspectives between the protagonist's and side characters' throughout the playthrough. The magical realism technique is clearly shown in how the environment is of a life-like world with magical elements such as usage of Persona and appearances of Shadows.

The protagonist of Persona 3 Portable, or the player, is difficult to elaborate as it often depicts as a silent protagonist (Atlus, 2009). It all depends on the player's choices in dialogues' options and actions taken to improve the character's stats. The protagonist too exists in two different genders that can be picked according to the player's preference. However, there are subtle 
hints of the protagonist's personality through their dialogue script and NPCs reaction to their presence. A pattern of compassion and gentleness is found in the female dialogue option while the male's side is indifferent yet caring. An example can be seen when Mitsuru Kirijo, a returning member of Specialized Extracurricular Execution Squad (SEES), declaring to join the fight in Tartarus. The male's bad choice will say she is unreliable while the female ones will ask in worry about her wellbeing. Since the male one is more canon to the series, the latter will be focused more on him. Throughout the game, the player will help people in trouble and form an unbreakable bond. They will start taking requests and doing favours showing how generous and kind-hearted they are to help others. The protagonist also appears to be calm since in the opening when they walk undisturbed in the Dark Hours, there are lines of coffins and pools of blood along the street. He is also considered reserve as an introvert since he mostly sitting through the conversation rather than joining in. It also applies to when the player decides to spend the weekend playing an online game at home all day. The symbolism of the protagonist is his blue hair, which coincides with the game's colour theme. It signifies the night, the Dark Hour, the coffins, and his fate.

The world or city in the game is created based on a real-life environment from the Atlus staff's point-of-view ("Persona 3 Portable", n.d.). It is closely detailed and resembles the setting within Shinakawa, Odaiba, and Haneda area in Tokyo. From there, Iwatodai city exists as a hybrid of the three mentioned. There are shops the player can visit, to buy gears and increase stats as well as clubs to attend in expanding Social Links. The game world heavily relies on the map. When the player wants to enter a certain area, they are to pick their option through the cursor by moving it around. It reveals another layer of mapping once the player enters the area they desired. During exploration in Tartarus however, is an area of the interconnected room. The area within each floor is limited but they can advance further upward by climbing the stairs entering another area. By accessing each floor, the player can befall an accident such as party members separating locations, no Shadows appear and there are mountains of rewards but The Reaper will come faster, the floor is scanned easily fully mapped, plus the floor becomes dark and there is no auto-map assistance. It shows that in life, accidents happen and they have to cope with it in the best possible way.

The NPC is mostly students from Gekkoukan School and bystanders in the city (Atlus, 2009). They are interactive and their dialogues change according to the period. The closer player is towards the next Full Moon Operations or 'The Fall', the grimmer the text boxes are. They also talk about nearing events such as their summer trip or changing of seasons in the game. The player can shop items like any other game and accept requests from people to get the special item or gain a new Social Link to strengthen their Persona. The MOBs are the Shadows. Their appearance in the map area is in the form of dark walking glob and the number of enemies depends on its size. The larger it is, the higher the number. The type of Shadow varies from time to time and it takes several strong Personas to defeat them by striking their weak points.

Free choices are implemented and some Social Links arc will continue even when the bad choice is picked (Atlus, 2009). The first-person view as the protagonist allows full control of the player. They have the option for an early game over when they kill Ryuji after his reveal as the appraiser of Nyx. If they let him live, which is the true choice, the game progress and the player will fight Nyx at the top of Tartarus. Within the female protagonist's storyline, the player can save Shinjiro Aragaki from his inevitable death in the male side's storyline by increasing their Social Links to a certain level. The player too can have full control of their party members during battle whether directly or mode setting through Fuuka's assistance but 
not story-wise. Characteristic, engagement, and response of the protagonist are up to the player's choice, giving freedom for them to shape themselves within the game world. The Velvet Room gives wider choices as the player can choose to fuse their Personas, recall discarded Persona, or taking Elizabeth's request. Players also free to engage in certain Social Links that could help them strengthen their Persona accordingly with each Arcana that resonates with mythology and such.

Shoji Meguro is a composer who works for Atlus in creating dormitory ambiance sound or BGM mostly for the Persona series (Greening, 2009; Mughal, 2019). His musical style spans several genres such as rock, electronic, jazz, classical, and J-pop. Meguro's style of music is being influenced by video game composers Koichi Sugiyama, Hiroshi Kawaguchi, as well as Beethoven, and Tchaikovsky. He often uses some English lyrics in his songs in the many Persona games. He stated that since most Japanese people not fully will understand them, it will not be as distracting as it would be in Japanese.

Persona 3 Portable's BGM is mostly themed around pop and lounge-jazz style of music. They can hear that through their BGM, that depicts a high sense of jazz genre for relaxation while the ones in Tartarus have pop-based rhythm and melody that gives out the sense of curiosity and a creepy vibe. What is interesting to pay attention to detail is the Tartarus floor's theme. It adds a new instrument in the background as the players ascend towards a new area, giving out the meaning of new enemies, increasing curiosity, and thrilling excitement that engulfs the character's soul. It makes the experience more symbolic.

The comparative analysis can be summarized as below:

\begin{tabular}{|c|c|c|}
\hline $\begin{array}{c}\text { STORYTELLING } \\
\text { TECHNIQUES }\end{array}$ & KINGDOM HEARTS II & PERSONA 3 PORTABLE \\
\hline (Narrative) Plot & $\begin{array}{l}\text { - } \text { Simple plot } \\
\text { - } \text { Light vs. darkness. } \\
\text { - } \text { acceptance theme } \\
\text { - } \text { Linear } \\
\text { - } \text { Have one absolute } \\
\text { ending } \\
\text { - Replayability low } \\
\text { - Events are pre- } \\
\text { - determined } \\
\text { - Scripted trajectory and } \\
\text { micro-narratives. } \\
\text { 'Push' narratives happen } \\
\text { a lot of times }\end{array}$ & $\begin{array}{l}\text { - Heavy storyline } \\
\text { - } \quad \text { Self vs. self, self vs. villain } \\
\text { - } \text { Revolved around death } \\
\text { and depressing themes } \\
\text { - } \quad \text { Linear } \\
\text { - Has two ending and } \\
\text { genders to play } \\
\text { - Replayability high } \\
\text { - Scripted trajectory and } \\
\text { - 'Pullo-narratives. } \\
\text { - 'Pusrative happens } \\
\text { occasionally }\end{array}$ \\
\hline
\end{tabular}




\begin{tabular}{|c|c|c|}
\hline Character & $\begin{aligned} & \text { Sora } \\
& \text { - } \text { A symbolism of } \\
& \text { friendship } \\
& \text { - } \text { Has an upbeat and } \\
& \text { simple-minded } \\
& \text { personality } \\
& \text { - No development } \\
& \text { - His drive source is his } \\
& \text { friends } \\
& \text { - Multiple Perspectivity }\end{aligned}$ & $\begin{array}{l}\text { Blue-haired boy/player } \\
\text { - A symbolism of night } \\
\text { - Personality depends on } \\
\text { player, some imply in } \\
\text { dialogue choices } \\
\text { - Development is through } \\
\text { - } \text { simulation gameplay } \\
\text { - His drive source is his } \\
\text { - Multiple Perspectivity }\end{array}$ \\
\hline Game World & $\begin{array}{l}\text { - Identical to the movie of } \\
\text { Disney's } \\
\text { - Has a big room layout } \\
\text { - Has less NPCs } \\
\text { - Interactivity in gameplay } \\
\text { is high, but does not in } \\
\text { story } \\
\text { - Choices in gameplay is } \\
\text { higher than story }\end{array}$ & $\begin{array}{l}\text { - } \quad \text { Identical to real life } \\
\text { - Has small layout } \\
\text { - Has many NPCs } \\
\text { - Interactivity is high both } \\
\text { in gameplay and story } \\
\text { - Choices in gameplay is } \\
\text { equal to story }\end{array}$ \\
\hline Sound & $\begin{array}{l}\text { - Orchestrated and pop } \\
\text { style } \\
\text { - The field theme follows } \\
\text { the movie's theme }\end{array}$ & $\begin{array}{l}\text { - Background music has } \\
\text { jazz and pop style } \\
\text { - Field theme in Tartarus } \\
\text { changes each level }\end{array}$ \\
\hline
\end{tabular}

Table 1: Analysis summary of Kingdom Hearts II and Persona 3 Portable storytelling techniques

Both games are entertaining and fun to play in their own ways. From the perspective of narrative themes, Persona 3 Portable is more interesting and mind boggling with death as their theme than Kingdom Hearts II simplistic darkness vs. light. Even so, Kingdom Hearts II has a unique combat system of Summons, Reaction Commands, and much more that allows player to arrange battle strategy according to their preference which equal to fun gaming. Persona 3 Portable too let the player have fun creating, fusing, and recruiting various Persona that will ease their battle. Its narrative is easy to understand and has less plot holes since for the most part, information is being dropped properly at an appropriate timeline within the story. More crucial plot and event happens as they proceed further into the narrative. Lastly is with lore, Kingdom Hearts II has less of them compared to Persona 3 Portable. Kingdom Hearts II has worlds of Disney's films that mirror their movie counterpart for most part of the journey, so it is hard to insert intriguing lore. Despite that, the existence of Nobody, Heartless, Organization XIII, and Kingdom Hearts makes up for it. Persona 3 Portable wins the lore comparison because of the Persona concept within the game that based on mythology and fairy tales. There are innumerable lore that can connect them through Social Links and those who presented as them. 


\section{Conclusion}

Kingdom Hearts II immersion is strong through their free combat system to choose and craft style they prefer. The player does not have the power to change the content of the plot and Sora's personality in their playthrough. Their narrative consists of 'push' micro-narratives and scripted trajectory considering the player's least participation and numbers of cut scenes, making the immersion process less enjoyable. Even so, their interactivity with the world is complete with information that there is no gap for imaginative thought. The simple narration makes up for the opportunity for emergent players to create a variety of player-constructed narrative. The lack of lore may be the explanation for this straightforward storyline.

On the other hand, Persona 3 Portable gives freedom to players inside and outside of combat situations. They let players have high involvement as the narrative has more 'Pull' script rather than 'Push'. The player's engagement in the story takes effect and makes a difference even though time still moving forward for them. Their interactivity is diverse and countless making the experience complete, though some information in the game is interpretive. Since the game is in the form of a visual novel, the player's presence is immersive as there are dialogue options and a silent protagonist. Persona 3 Portable is a true RPG that gives the player the complete experience of immersion with high freedom interactivity both in gameplay and story. The game is enjoyable as they can control their party members in the turn-based combat system and has heavy lore according to the respective Social Links and Persona.

\section{References}

Pong, A. (n.d.). http://www.computinghistory.org.uk/det/4007/Atari-PONG/

Ang, C. S. (2005). Rules, gameplay and narratives in video games.

https://www.researchgate.net/publication/236870305_Rules_gameplay_and_narrativ es_in_video_games

Atlus. (2009). Persona 3 portable. [Playstation portable]. Atlus.

Christy, M. (2010). Write your way into animation and games. Focal Press.

Crafty TV Writing. (2020). Chapter 4 : Bad writing and how to fix it (or at least get away with it). http://www.craftyscreenwriting.com/excerpts/TV05.html

Dangcil, S. (2017). 15 major plot holes in kingdom hearts. https://www.thegamer.com/15major-plot-holes-in-kingdom-hearts/

Greening, C. (2009). Shoji Meguro biography. https://www.squareenixmusic.com/composers/meguro/biography.shtml

Greening, C. (2007). Yoko Shimomura. https://www.squareenixmusic.com/composers/shimomura/index.shtml

Hurme Jarkko. (2016). Storytelling in video games (Bachelor's thesis), Turku University of Applied Sciences, Finland.

Kingdom hearts II. (n.d.). https://kingdomhearts.fandom.com/ wiki/Kingdom_Hearts_Wiki:Main_Page

Lemmens, P. (2016). Narrative in video games environmental storytelling in Bioshock and Gone Home. https://lib.ugent.be/catalog/rug01:002375924

List of narratives techniques. (2017). http://self.gutenberg.org/articles/Literary_technique

Madigan, J. (2010). The psychology of immersion in video games. https://www.psychologyofgames.com/2010/07/the-psychology-of-immersion-invideo-games/ 
Mughal, H. A. (2019). Support at Work and its Relationship with Employee Performance:

Critical Insights for Early Scholars. Annals of Contemporary Developments in Management \& HR (ACDMHR), 1(3), 16-21.

Persona 3 portable. (n.d.). https://megamitensei.fandom.com/wiki/Megami_Tensei_Wiki Stephen, T., S., Michael, Y., Roger, T., \& Beomkyu, C. (2015). Game narrative, interactive fiction, and storytelling: creating a "time for telling" in the classroom. https://www.researchgate.net/publication/284730579_Game_Narrative_Interactive_ Fiction_and_Storytelling_Creating_a_Time_for_Telling_in_the_Classroom

Sora. (n.d.). In khwiki. https://www.khwiki.com/Sora

Stuart, K. (2016). Why is video game lore so awful? https://www.eurogamer.net/articles/2016-04-23-against-the-lore

Square Enix product development division 1. (2005). Kingdom Hearts II. [Playstation2]. Square Enix.

The power of storytelling. (n.d.). http://www.frogleaps.org/blog/topic/what-is-the-powerof-storytelling/

Pickvance, C. G. (2001). Four varieties of comparative analysis. Journal of Housing and the Built Environment 16: 7-28, 2001. https://www.researchgate.net/publication 